\title{
Study on Home Range Size and Pattern among Three Diurnal Non-Human Primates in Mihintale Wildlife Sanctuary in Sri Lanka
}

\author{
Kumara H.W.R. ${ }^{1}{ }^{*}$, Nahallage C.A.D. ${ }^{1}$, Huffman M.A. ${ }^{2}$ \\ ${ }^{1}$ University of Sri Jayewardenepura, Sri Lanka \\ ${ }^{2}$ Kyoto University, Japan
}

\begin{abstract}
The size and pattern of a primate home range depends basically on the availability of distribution of food, the density of the group, free-ranging species and geographical factors. When considering about Sri Lankan primates; Sri Lanka is home to five primate species. Three species belongs to catarrhines, the toque monkey (Macaca sinica), the purple-faced langur (S. vetulus), the grey langur (S. priam thersites) and two or more species of the slender loris (Loris spp.). This study was conducted in Mihinthale wildlife sanctuary and focused on the home range of the toque monkey (Macaca sinica sinica), the purple-faced leaf langur (S. vetulus philbrick), and the grey langur (S. priam thersites). Preliminary observations were started from January 2015 to May of 2015. Intensive data collection was started from May 2015 to September, 2016. Behavioural observations were conducted for 136 days. Three groups were selected randomly to represent all three species for this long term study. Home range data was collected by observations of daily path range of the three species. To determine the actual home range of the three species GPS points and hard copies of maps of the site were used. GIS maps were created to illustrate the area used by each species. The results of the home range sizes of each species indicated that the purple-faced-leaf langur's home range is the largest among the three species. All macaque groups have a minimum home range when compare with the other two langur species. Macaques mainly depend on human-supplied food and hardly depend on the food from the forest, hence recording the smallest home range among the three primate species. The study concludes that purple - faced leaf langur's home range is the largest home range than gray langur and toque macaque. Gray langur's home range is larger than toque macaques and smaller than purple-faced leaf langur. Toque macaque has the smallest home range. The identified two main factors for this difference are the availability of food and the density of groups in the given area.
\end{abstract}

KEYWORDS: food availability, group size, Diurnal, Primate, Home Range 


\section{INTRODUCTION}

A home range is a particular area in which an animal lives and moves on a periodic basis, and it is related to the concept of an animal's territory, which is the area that is actively defended. Historical evidence suggests that Mihintale is the oldest Sri Lankan wildlife sanctuary (Geiger, 1934; Kumara et al., 2018). Many parts of the dry zone had been cleared at different times for central agriculture between 800 to 2000 years ago (Holmes, 1958). However, with the dwindling of ancient civilization in Anuradhapura around 1200 A.D and with the changing of the kingdom's capital from Anuradhapura to Polonnaruwa, the region was abandoned by about 700 years ago (Dittus, 1985). The forest cover in Mihintale, including many dry zone forests, are considered to be secondary (Holmes, 1958). Mihintale is noteworthy as the world's oldest wildlife sanctuary, established more than 2200 years ago (Epigraphia Zeylanica, 1928). Mihintale wildlife sanctuary is located in the Anuradhapura District, North-Central Province, Sri Lanka, covering about 2,470 acres (999.6 Ha) Unanthanna et al., 2010). It comprises semi deciduous forest, scrublands, water-edge habitats, highly degraded tertiary forests and other vegetation in the archaeological sites (Kumara et al., 2018). The Kaludiyapokuna forest (KPF) has semideciduous forests dominated by Ficus spp, Drypetes ebunum, Schleichera oleosa, Drypetes spp, Schleichera oleosa, Dialium ovoideum and Dimocarpus longan (Unanthanna et al., 2010). The main objective of this study was to identify the home range size of three sympatric primate species in the Mihintale wildlife sanctuary in Anuradhapura District. Sri Lanka is an important place to study primates because it is home to five primate species (Dela, 2007; Rudran, 2007; Nahallage et al., 2008). These species include three catarrhines, the toque monkey ( $M$. sinica sinica), the purple -faced langur (S. vetulus philbrick), the grey langur (S. priam thersites) and two species of slender loris (Loris spp.). Numerous studies have shown that food availability plays a key role in determining primate biomass and home range (Kay et al., 1997).

\section{METHODOLOGY}

Preliminary observations were started from January 2015 to May of 2015. Intensive data collection was started from May 2015 to September 2016 totaling to 697 observation hours. Before this, three months (January to March 2015) were spent on habituating the monkeys in each troop to the presence of the research and to establishing individual identification of each monkey. The total period of the daily path and home range in the study period was 136 days (including pilot research) which started from January 2015 and continued till September 2016. The total study period divided into three main periods according to different seasons. Period I was from April to September 2015 ( $1^{\text {st }}$ Dry season), Period II (Rainy season) was from October to March 2016, and period III was from April to September 2016 ( $2^{\text {nd }}$ Dry season). Three groups were selected randomly to represent all three species by randomly for this long term study. Home range data was collected by observations of daily path range. To determine the actual home range 
of the three species GPS points and hard copies of maps of the site were used. GIS maps were created to illustrate the area used by each species Arc desktop ten software was used to create the maps. Satellite images (last updated on 10 January 2018 in Google earth) were downloaded from Google map saver version 1.03 and were geo-referenced.

\section{RESULTS \& DISCUSSION}

The whole study period was divided into three main periods. $1^{\text {st }}$ and $3^{\text {rd }}$ periods as dry seasons and the second period as the rainy season. The total home range size during the $1^{\text {st }}$ dry season of $S$. priam thersites, S. vetulus philbrick and $M$. sinica sinica groups were 9.6 ha, 9.3 ha and 6.9 ha respectively. During the rainy season the total home range size were 5.3 ha, 15.8 ha and 7.1 ha respectively. In the $2^{\text {nd }}$ dry season, $S$. priam thersites, $S$. vetulus philbrick and $M$. sinica sinica groups were 8.9 ha 12.1 ha and 6.1 ha respectively (Fig 1, 2 and 3). The use of space as a defended territory or an undefended home range is dependent upon the resources that it contains. The overlap between $S$. vetulus philbrick and $S$. priam thersites groups were extensive (7.2 ha) during the period of the $1^{\text {st }}$ dry season, while the overlap between $S$. vetulus philbrick and S. priam thersites groups were minimal ( 5.7 ha) during the $2^{\text {nd }}$ dry season (Fig.4). The overlap between $S$. vetulus philbrick and $M$. sinica groups were extensive (5.2 ha) during the period of rainy season, while the overlap between $S$. vetulus philbrick and $M$. sinica sinica groups were minimal (4.3 ha) during the $1^{\text {st }}$ dry season. The overlap between group
S. priam thersites and group $M$. sinica sinica was extensive (4.8 ha) during the period of rainy season, while the overlap between group $S$. vetulus philbrick and group M. sinica sinica was minimal (2.3 ha) during the raining season. Food resources are important for determining home range size. The results of this study show that $S$. vetulus philbrick and S. priam thersites at Mihintale different in several aspects of their ranging behaviour. The biggest home range size out of the three species was recorded from $S$. vetulus philbrick and the smallest home range was recorded from $M$. sinica sinica. Home range size is known to decrease with the increase in food resources (McKey et al., 1982).

In comparison, during all three periods of study of the home range sizes, the largest home range was identified from the $S$. vetulus philbrick and smallest home range size was identified from $M$. sinica sinica. Home range size within species has also been shown to increase with group size and decrease concerning the density of conspecifics (Vandacone, 2011). According to Vandercone (2011), at Kaludiyapokuna it was shown that larger home range size for $S$. vetulus philbrick could be due to large group size than $S$. priam thersitesas as a result of a comparatively low density of conspecifics. Present study found that the three species' home range sizes were different from previous findings of other colobine and macaque species (Table 1). At Polonnaruwa the average group size for $S$. vetulus philbrick was 8.4 and it is one of the highest for colobine populations in the world (Davies, 1994). There were a few 
important differences in the home ranges of the three species in Mihintale from other sites, specifically home range size. The three species home ranges were smaller in when compared to the same species in Polonnaruwa and other Asian counties. However, Kaludiyapokuna was similar to Mihintale. The discrepancy in home ranges reported for $S$. priam thersites in this study and previous studies may be due to differences in the sizes of the study groups, density of conspecifics, or differences in resource availability between study localities. Since the vegetation compositions within the home ranges of both groups were relatively similar, and the availability of provisioned food was also relatively similar. However, it is unlikely that the difference in home range sizes between $S$. priam thersites and S. vetulus philbrick were due to differences in resource availability. The individual density of S. priam theirsites and $M$. sinica sinica was greater than that reported by other studies.

Table 1: A comparison of home range size on Colobine species and Macaque species in Asia

\begin{tabular}{|l|c|l|l|}
\hline \multicolumn{1}{|c|}{ Species } & Home range (ha) & Study site & \multicolumn{1}{c|}{ Reference } \\
\hline S. vetulus philbrick & 11 & Sri Lanka & Vandercone, (2011) \\
\hline S. priam theirsites & $10-15$ & Sri Lanka & Hladik, (1977) \\
\hline S. priam thersites (Group A) & 9.4 & Sri Lanka & Vandercone, (2011) \\
\hline S. priam thersites (Group B) & 7.8 & Sri Lanka & Vandercone, (2011) \\
\hline M. fascicularis & $09-18$ & Singapore & Sha \& Hanya, (2013) \\
\hline M. fuscata & 370 & Japan & Fooden and Aimi, (2005) \\
\hline M. mulatta & 1600 & China & Southwick et al., (1996) \\
\hline M. larvatus & 138 & Malaysia & Matsuda et al., (2009) \\
\hline T. leucocephalus & 23.8 & China & Zhou et al., (2011) \\
\hline T. francoisi & 19 & China & Zhou et al., (2011) \\
\hline M. mulatta & 453 & Bangladesh & Shoma \& Feeroz, (2014) \\
\hline M. nemestrina & $60-825$ & Thailand & Caldecott, (1986) \\
\hline M. nigra & $156-725$ & Indonesia & O'Brien \& Kinnaird, (1997) \\
\hline P. melalophus & 30 & Malaysia & Bennett, (1986) \\
\hline P. potenziani & 33 & Indonesia & Fuentes, (1996) \\
\hline M. tonkeana & $353-735$ & Indonesia & Riley, (2008) \\
\hline M. s. aurifrons & 64 & Sri Lanka & Weerasekara \& Ranawana, (2017) \\
\hline S. priam thersites (Period 01) & 9.6 & Sri Lanka & This study \\
\hline S. priam thersites (Period 02) & 5.3 & Sri Lanka & This study \\
\hline S. priam thersites (Period 03) & 8.9 & Sri Lanka & This study \\
\hline S. vetulus (Period 01) & 9.3 & Sri Lanka & This study \\
\hline S. vetulus (Period 02) & 15.8 & Sri Lanka & This study \\
\hline S. vetulus (Period 03) & 12.1 & Sri Lanka & This study \\
\hline M. sinica (Period 01) & 6.9 & Sri Lanka & This study \\
\hline M. sinica (Period 02) & 7.1 & Sri Lanka & This study \\
\hline M. sinica (Period 03) & 6.1 & Sri Lanka & This study \\
\hline & & & \\
\hline
\end{tabular}




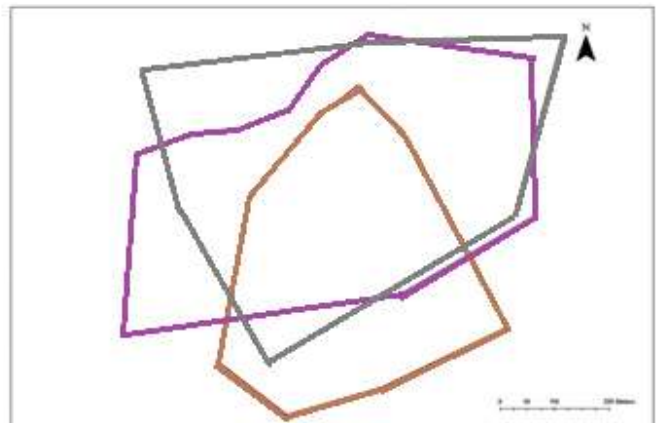

Figure 1. Home ranges of $S$. priam thersites (gray colour), $S$. vetulus (purple colour) and M. sinica (brown colour) group during the $1^{\text {st }}$ day season

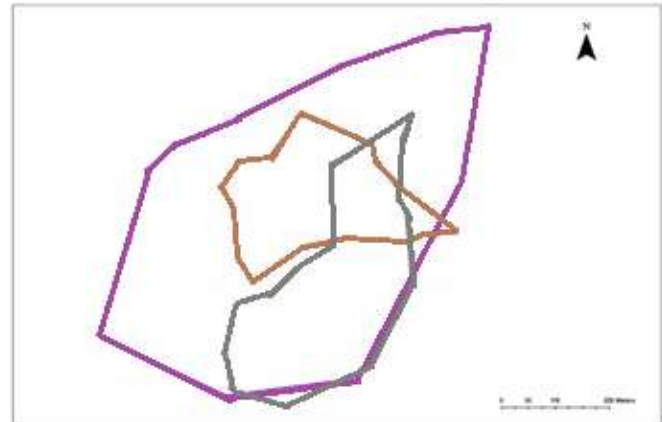

Figure 2. Home ranges of S. priam thersites (gray colour), S. vetulus (purple colour) and M. sinica (brown colour) group during the rainy season

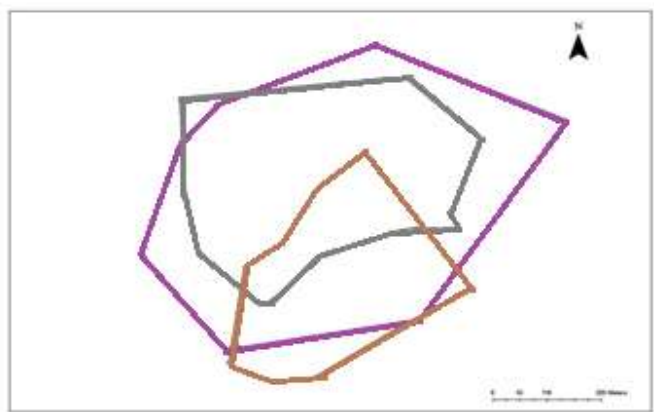

Figure 3. Home ranges of $S$. priam thersites (gray colour), S. vetulus (purple colour) and M. sinica (brown colour) group during the $2^{\text {nd }}$ day season

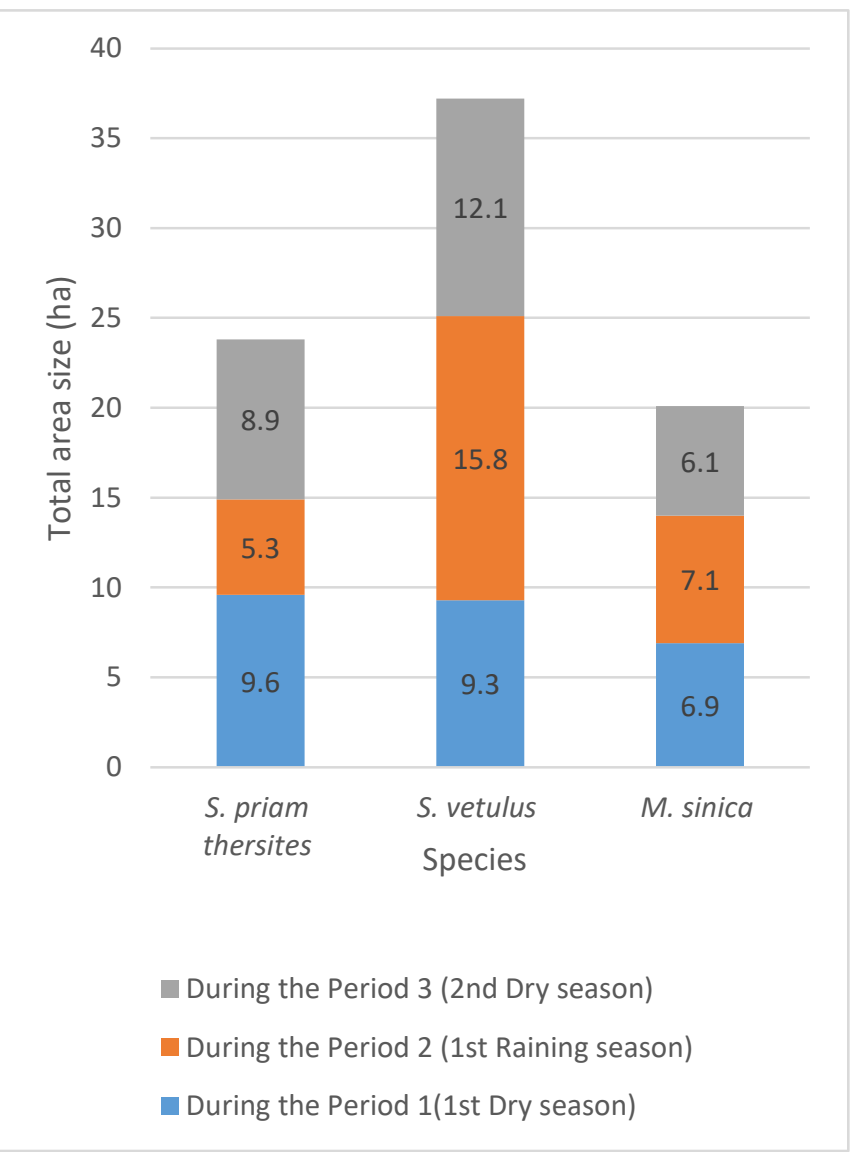

Figure 4. The comparison of home range sizes of three species 


\section{CONCLUSION}

The study concludes that purple-faced leaf langur's home range is the largest home rage than gray langur and toque macaque. Gray langur's home range is larger than toque macaque and smaller than purplefaced leaf langur. Toque macaque has the smallest home range. The three species home ranges were smaller in comparison with the species in Polonnaruwa and other Asian counties. Similar associations between group size and home range size have also been observed in other folifrugivorous primates (Chapman, 1989).

\section{LIST OF REFERENCE}

Bennett, E. L., and Davies, A. G. (1994). The ecology of Asian Colobines. In A. G., Davies, J. F., Oates (Eds.), Colobine Monkeys: Their Ecology Behaviour and Evolution Cambridge: Cambridge University Press. 129- 171.

Caldecott, J. O. (1986). An ecological and behavioural study of the pig-tailed macaque. New York: Karger. 262.

Chapman, C. A. (1989). Primate seed dispersal: The fate of dispersed seeds. Biotropica 21, 148-154

Davies, G. A. (1994). Colobine populations. The natural history of African colobines. In A.G. Davies, \& J.F. Oates (Eds.), Colobine Monkeys: Their Ecology Behaviour and Evolution., Cambridge: Cambridge University Press. 285-310.

Dela, J. (2007). Seasonal food use strategies of Semnopithecus vetulus nestor, at Panadura and Piliyandala, Sri
Lanka. International Journal of Primatology, 28, 607-626.

Dittus, W. P. J. (1985). The influence of cyclones on the dry evergreen forest of Sri Lanka. Biotropica, 17, 1-14.

Fooden, J., \& Aimi. M. (2005). Systematic review of Japanese macaques, Macaca fuscata. Fieldiana Zoology. 104: 1-200.

Fuentes, A. (1996). Feeding and ranging in the Mentawai Island langur (Presbytis potenziani). International Journal of Primatology, 17, 525-548.

Geiger, W. (1934). The Mahawamsa (The Great Chronicle of Ceylon-Sri Lanka) OxforUniversity Press London.

Hladik C. M. (1977). A comparative study of the feeding strategies of two sympatric species of leaf monkeys: Prebytis senex and Presbytis entellus. In T. H. CluttonBrock (Ed.), Primate Ecology: Studies of feeding and ranging behaviour in lemurs, monkeys and apes (323-353), New York: Academic Press.

Holmes, C. H. (1958). The broad pattern of climate and vegetational distribution in Ceylon. Ceylon Forester, 2: 209-225.

Kay, R. F., Madden, R.H., Van Schaik, C., \& Higdon, D. (1997). Primate species richness is determined by plant productivity: Implications for conservation. Proceedings of the National Academy of Sciences USA, 94, 1302313027.

Kumara, H. W. R., Nahallage C.A.D., Huffman, M.A (2018). Perceptions and 
Attitudes among Venders towards Nonhuman Primates in Mihintale Wildlife Sanctuary in Sri Lanka. International Journal of multidisciplinary Studies, 5(2).

Matsuda, I., Tuuga, A., \& Higashi, S., (1996). Ranging behavior of proboscis monkeys in the riverine forest with special reference to ranging in inland forest. International Journal of Primatology, 30, 313-325.

McKey, D. B., Gartlan, J. S., Waterman, P. G., \& Choo, G. M., (1981). Food selection by black colobus monkeys (Colobus satanas) in relation to plant chemistry. Biological Journal of the Linnean Society, 16, 115-146.

Nahallage, C. A., Huffman, M. A., Kuruppu, N. and Weerasingha, T. (2008). Diurnal Primates in Sri Lanka and People's Perception of Them. Primate Conservation, 23(1), 81-87.

O'Brien, T., \& Kinnaird, M. (1997). Behaviour, diet and movement of the Sulawesi crested black macaque (Macaca nigra). International Journal of Primatology 18: 321-351

Riley, E. P. (2008). Ranging patterns and habitat use of Sulawesi Tonkean macaques (Macaca tonkeana) in a humanmodified habitat. American Journal of Primatology: Official Journal of the American Society of Primatologists, 70(7), 670-679.

Sha, J. C. M., \& Hanya, G. (2013). Diet, activity, habitat use, and ranging of two neighboring groups of food-enhanced long-tailed macaques (Macaca fascicularis). American Journal of Primatology, 75(6), 581-592.

Shoma, S. F., \& Feeroz, M. M. (2014) Population organization and ranging pattern of Rhesus macaque (Macaca mulatta) at Bandar, Narayanganj. Jahangirnagar University Journal of Biological Sciences, 3(1), 2735.

Southwick, C. H., Zhang Y. Z., Jiang H. S., Liu Z. H. \& Qu, W. (1996). Population ecology of rhesus macaques in tropical and temperate habitats in China. In: (J.E. Fa and D.G. Lindburg, eds.). Evolution and ecology of macaque societies. Cambridge University Press, Cambridge. 95-105.

Unanthanna, W. M. J. R. K. W. and Wickramasinghe, S. (2012). Population distribution, Threats and conservation status of Semnopithecus priam thersites at Mihintale sanctuary, Sri Lanka. In Proceedings of International Forestry and Environment Symposium , 15(1).

Vandercone, R. (2011). Dietary Shifts, Niche Relationships and Interspecific Competition in Sympatric Grey Langur (Semnopithecus entellus) and Purple-faced Langur (Trachypithecus vetulus) in Sri Lanka. All Theses and Dissertations (ETDs).

Waterman, P. G., Ross, J. A. M., Bennet, E. L., \& Davies, A. G. (1988). A comparison of the floristics and leaf chemistry of the tree flora in two 
Malaysian rain forests and the influence of leaf chemistry on the populations of colobine monkeys in the old world. Biological Journal of the Linnean Society, 34, 1-32.

Weerasekara, W., \& Ranawana, K. (2017). Ranging pattern of dusky toque macaques (Macaca sinica aurifrons) inhabiting Peradeniya university premises, Sri Lanka.

Zhou, Q., Tang, X., Huang, H., \& Huang, C. (2011). Factors affecting the ranging behavior of white-headed langurs (Trachypithecus leucocephalus). International Journal of Primatology, 32, 511-523. 